\title{
Staff perceptions of patient safety culture in general surgery departments in Turkey
}

\author{
Mesut Teleş ${ }^{1}$, Sidika Kaya $^{2}$
}

\begin{abstract}
1. Department of Health Care Management, Faculty of Economics and Administrative Sciences, Hacettepe University.

2. Department of Health Care Management, Faculty of Economics and Administrative Sciences, Hacettepe University.
\end{abstract}

\section{Emails:}

Mesut Teleş: mesutteles@hacettepe.edu.tr

Sid1ka Kaya: sdkaya@hacettepe.edu.tr

\begin{abstract}
Background: The first step towards establishing and improving patient safety culture in hospitals is measuring patient safety culture perceptions of staff. Few studies have examined the perception of patient safety culture in general surgery departments.

Objectives: The objective of this study was to evaluate patient safety culture and patient safety grade in general surgery departments and to examine the relation between the patient safety culture and the patient safety grade.

Methods: This study examined patient safety culture and patient safety grades of 124 staff in seven surgery departments of a hospital in Turkey. The staff completed the hospital survey on patient safety culture and answered questions about their professional characteristics. One-way ANOVA, Independent-samples t test, corrected chi-square test, multiple correspondence analysis and Eta co-efficient were used in statistical analyses.

Results: The patient safety dimension of "teamwork within units" had the highest mean and percentage of positive responses. The "frequency of events reported" and "non-punitive response to errors" had the lowest means and percentages of positive responses. Participants with resident or nurse positions, < age 31 years, with $<6$ years of professional experience, and 60 or more work hours/week, had significantly more negative perceptions of patient safety culture than other participants. Patient safety grades and the dimensions of "management support for patient safety" and "overall perceptions of patient safety" had significantly high Eta coefficients.

Conclusion: Frequency of events reported and non-punitive responses to errors should be improved, and participants' characteristics should be considered at improvement efforts in general surgery departments. The dimesions with low means suggest opportunities for improvement.
\end{abstract}

Keywords: Patient safety culture, Turkey, general surgery, multiple correspondence analysis.

DOI: https://dx.doi.org/10.4314/ahs.v19i2.46

Cite as: Teles M, Kaya S. Staff perceptions of patient safety culture and grades in general in Turkey. Afri Health Sci.2019;19(2): 2208-2218. https:/ / dx.doi.org/10.4314/abs.v19i2.46

\section{Corresponding author:}

Mesut Teleş,

Hacettepe University, Faculty of Economics and

Administrative Sciences, Department of Health

Care Management, Beytepe Campus, 06800,

Ankara, Turkey

Fax: +90 3122976359

Phones: +903122976356-

+903122976357 - +903122976358

Mobile Phone: +90 5055188048

E-mail: mesutteles@hacettepe.edu.tr

\section{Introduction}

Patient safety culture, an aspect of the general culture of an institution, has become an international priority for health institutions. ${ }^{1}$ A sound safety culture can minimize medical errors and a robust safety culture can prevent medical errors that can cost human lives. ${ }^{2}$ In most health institutions that perform procedures based on safety programs, a safety culture develops, and harm to patients decrease. $^{3}$

The National Patient Safety Foundation in United States has defined patient safety as the avoidance, prevention

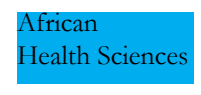

C 2019 Teleş et al. Licensee African Health Sciences. This is an Open Access article distributed under the terms of the Creative commons Attribution License (https://creativecommons.org/licenses/BY/4.0), which permits unrestricted use, distribution, and reproduction in any medium, provided the original work is properly cited. 
and amelioration of adverse outcomes or injuries stemming from the processes of health care. ${ }^{2}$ Patient safety culture is a part of organizational culture and consists of the attitudes, beliefs, perceptions, and values that employees share in relation to patient safety. ${ }^{4}$ Patient safety grade is how well or badly the staff evaluates the unit in which they work in the hospital in terms of patient safety in general. $^{5}$

Turkey's health sector has witnessed a rapid transformation in recent years. Based on its Strategic Plan (20132017), the aim of Turkey's Ministry of Health is to "improve the quality and safety of health services. ${ }^{6}$ Thus, the "Ministry of Health Instruction for the Development of Institutional Quality and for the Assessment Performance of Inpatient Treatment Institutions" was prepared in 2005. The most important parameter of the instruction was the development of quality criteria, which were revised over time, and the document, composed of 1,100 assessment criteria, was renamed the Quality Standards in Health-Hospital (Version 5), as of 1 July 2015. The fundamental aim of the Quality Standards in Health-Hospital was to build a "Safe Hospital". As part of "Safe Surgery Saves Lives," a project launched by the World Health Organization (WHO) in 2008, the "Safe Surgery Practical Guide" was released in accordance with the Quality Standards in Health- Hospital (Version 5) by the Ministry of Health. ${ }^{8}$ Many conferences and symposiums have been held regularly by Turkey's Ministry of Health to improve the quality of care and patient safety. ${ }^{9}$ All these activities indicate that Turkey attaches importance to establishing and improving patient safety in health institutions on a national level.

The first step to establish and improve patient safety culture in hospitals is to measure the patient safety culture of all the hospital staff. ${ }^{10}$ Staff perceptions, which support the sustainment of patient safety, are an important measure. ${ }^{3}$ International accreditation bodies require the evaluation of the institution's patient safety culture; it determines the strengths and weaknesses of health institutions regarding patient safety; it helps determine patient safety problems within care units; and it provides data for comparisons of performance among hospitals. ${ }^{11}$ Patient safety outcomes are used in evaluating the patient safety culture. Patient safety outcomes, including staff mem- bers' perceptions of safety, the willingness of staff members to report events, the number of events reported, and the overall patient safety grade given by staff members to their units, have been used to evaluate patient safety culture. $^{5}$

Surgical practices sometimes lead to irreversible consequences that affect patient safety. ${ }^{12}$ Several factors may negatively affect patient safety in hospitals, especially in general surgery departments. Surgical units have a high potential for danger i.e., injury to patients. ${ }^{13}$ According to the WHO, in developed countries, nearly half of all the adverse events (51-62\%) are related to surgical procedures. ${ }^{14}$ A strong patient safety culture in surgical units is required to provide a high level of safe care. Nevertheless, few studies have focused on surgical units. ${ }^{13}$ The objective of this study was, therefore, to evaluate perceptions of patient safety culture and patient safety grades related to the characteristics of the staff in general surgery departments. Furthermore, it aimed to examine the relationship betwee patient safety culture and the patient safety grades.

\section{Methods \\ Data collection Tool}

The Hospital Survey on Patient Safety Culture (HSPSC) was used in the study. It was developed in 2004 in the USA by the Agency for Healthcare Research and Quality. This tool is available at the AHRQ website. ${ }^{15}$ It is a widely used tool to measure patient safety culture in hospitals. ${ }^{16}$ HSPSC measures patient safety culture by 42 items, composing 12 dimensions. These 12 dimensions were used to measure perceptions of safety culture, and an additional one-item from the HSPSC was used to measure perceptions of patient safety grades by the staff. ${ }^{17}$ The HSPSC was adopted and validated in Turkish by Filiz (2009) who used exploratory factor analysis, which yielded factor loadings above .40 for the items. ${ }^{18}$ The internal reliabilities for the dimensions, as measured by Cronbach's $\alpha$, were .57-.86 and for all the items, it was 0.88; the Spearman-Brown coefficient was $.84 .{ }^{18,19}$ In this study, Cronbach's $\alpha$ for all the items on the Turkish version of the HSPSC was .89 and the Spearman-Brown coefficient was .76. Except for the "staffing" dimension $(\alpha=.13)$, Cronbach's $\alpha$ for the other dimensions was above 49 . As 18 of the items on the scale were negatively worded, they were reverse coded when entered into SPSS 20.0. A 
5-level Likert scale ranging from strongly disagree/never $=1$ to strongly agree/always $=5$ was used. In addition, to these items, participants answered questions regarding patient safety grades and the frequency of reporting events. Perceptions of patient safety grade of the staff was measured by "Please give your work are/unit in this hospital an overall grade on patient safety (excellent $=5$, failing=1)"; number of events reported was measured by "In the past 12 months, how many event reports have you filled out and submitted" questions. ${ }^{5}$

\section{Population and sample}

The study was conducted in a training and research hospital in Turkey and the population $(\mathrm{N}=166)$ consisted of all staff (surgeons-specialist physicians, residents, nurses, cleaning staff, security and others) working in its seven general surgery departments. The survey was administered to staff that interacted with the patients because the HSPSC's purpose is to assess the patient safety culture based on the perceptions of staff. ${ }^{5}$ Participation in the study was voluntary. The survey cover letter outlined the purpose of the survey and stated that the data were to be reported only in aggregate. The study was performed between June 20, 2011 and July 8, 2011. The researchers recruited participants by visiting seven general surgery departments within the hospital during a 3-day period. Once departments were visited and survey packets were distributed, the departments were revisited; the resulting response rate was $74.9 \%$ of the staff members. A total of 124 staff members including 26 surgeons (response rate $64.9 \%$ ), 24 residents (response rate 68.6\%), 38 nurses (response rate $89.5 \%$ ), and 51 other (response rate $78.4 \%$ ) participated in the study.

\section{Data analysis}

The data were analyzed using the SPSS 20 and STATISTICA 10 programs. The characteristics of the staff, the patient safety grade, and the frequency of reporting events were calculated and reported as frequencies and percentages. One-way ANOVA was used to compare the patient safety culture dimensions by characteristics of the participants including position, age and years employed in the profession and patient safety grades. Independent-samples $t$ test was used to compare the patient safety culture dimensions by hours worked per week by the participants. Parametric assumptions were tested using the homogeneity of variance test. Corrected chi-square test was used to compare the patient safety grades by participants' characteristics.

A multiple correspondence analysis was performed using the STATISTICA program to examine the relationship between all the characteristics of the staff and their patient safety grades they assigned. Correspondence analysis is an exploratory technique based on well-known geometrical paradigms. ${ }^{20} \mathrm{It}$ is a multivariate descriptive statistical method used to examine relationships between variables via two-dimensional or multi-dimensional cross-tabulations. ${ }^{21}$ The primary purpose of correspondence analysis is to produce a simplified data matrix from a complex one (cross-tabulation) without a considerable data loss. In other words, it is intended to explain the coherence of variable categories by representing them with a new and more simplified matrix and graphic. ${ }^{21,22}$ The type of correspondence analysis used to examine cross-tabulations with three or more variables is known as multiple correspondence analysis. ${ }^{21}$ In this study, the relationships between patient safety grade and the dimensions of patient safety culture were examined using the Eta statistic. The Eta coefficient may also be used as a measure of the relationship among changes in means of more than two groups. ${ }^{23}$ For this purpose, Eta statistics were calculated using ANOVA.

\section{Results}

Approximately $40.4 \%$ of the participants were physicians and $27.3 \%$ were nurses; $44.4 \%$ comprised the $31-40$ yearold age group and $78.2 \%$ worked $<60$ hours per week. Almost half $47.6 \%$ of the participants assigned a patient safety grade of acceptable to their units and $79.8 \% \mathrm{had}$ not filled out any event reports in the past 12 months (Table 1). 
Table 1. Characteristics of Respondents, Patient Safety Grade, and the Number of Events Reported ( $N=124)$

\begin{tabular}{lcc} 
& $\mathrm{N}$ & $\%$ \\
\hline Position & & \\
Surgeon & 26 & 21.0 \\
Resident & 24 & 19.4 \\
Nurse & 34 & 27.3 \\
Other* & 40 & 32.3 \\
Years Employed in the Profession & & \\
$<6$ & 47 & 37.9 \\
$6-10$ & 33 & 26.6 \\
$>10$ & 44 & 35.5 \\
Hours Worked per Week & & \\
$<60$ & 97 & 78.2 \\
60 and more & 27 & 21,8 \\
Age & & \\
$<31$ & 34 & 27.4 \\
$31-40$ & 55 & 44.4 \\
$>40$ & 35 & 28.2 \\
Patient Safety Grade & & \\
Excellent/Very good & 42 & 33.9 \\
Acceptable & 59 & 47.6 \\
Poor/Failing & 23 & 18.5 \\
Number of Events Reported & & \\
No Events & 99 & 79.8 \\
1 to 2 Events & 22 & 17.7 \\
3 Events or More & 3 & 2.4 \\
\hline
\end{tabular}

*7 Secretaries, 4 Dieticians, 3 Waiters, 22 Nurses looking after patients, 4 Security staff

The mean scores on the HSPSC's 12 dimensions of patient safety culture by participants' characteristics are presented in Table 2 as composite scores, which were based on calculations of the percentages of positive responses to the items ("agree/strongly agree" and "most of the time/ always"). "Teamwork within units" had the highest mean score $(4.06 \pm 0.64)$ and the highest percentage of positive responses (85\%), whereas, "frequency of event reports" and "non-punitive responses to errors" had the lowest means $(2.73 \pm 1.13 ; 2.73 \pm 0.71$, respectively) and percentage of positive responses $(32 \%)$. The mean scores on the dimensions of patient safety culture of those in resident or nurse positions, $<31$ years old, with $<6$ years of professional employment, and 60 and more hours/week of work were lower than those of the staff in the other groups. 
Table 2. Mean scores on the patient safety culture dimensions by participants' characteristics, and composite scores

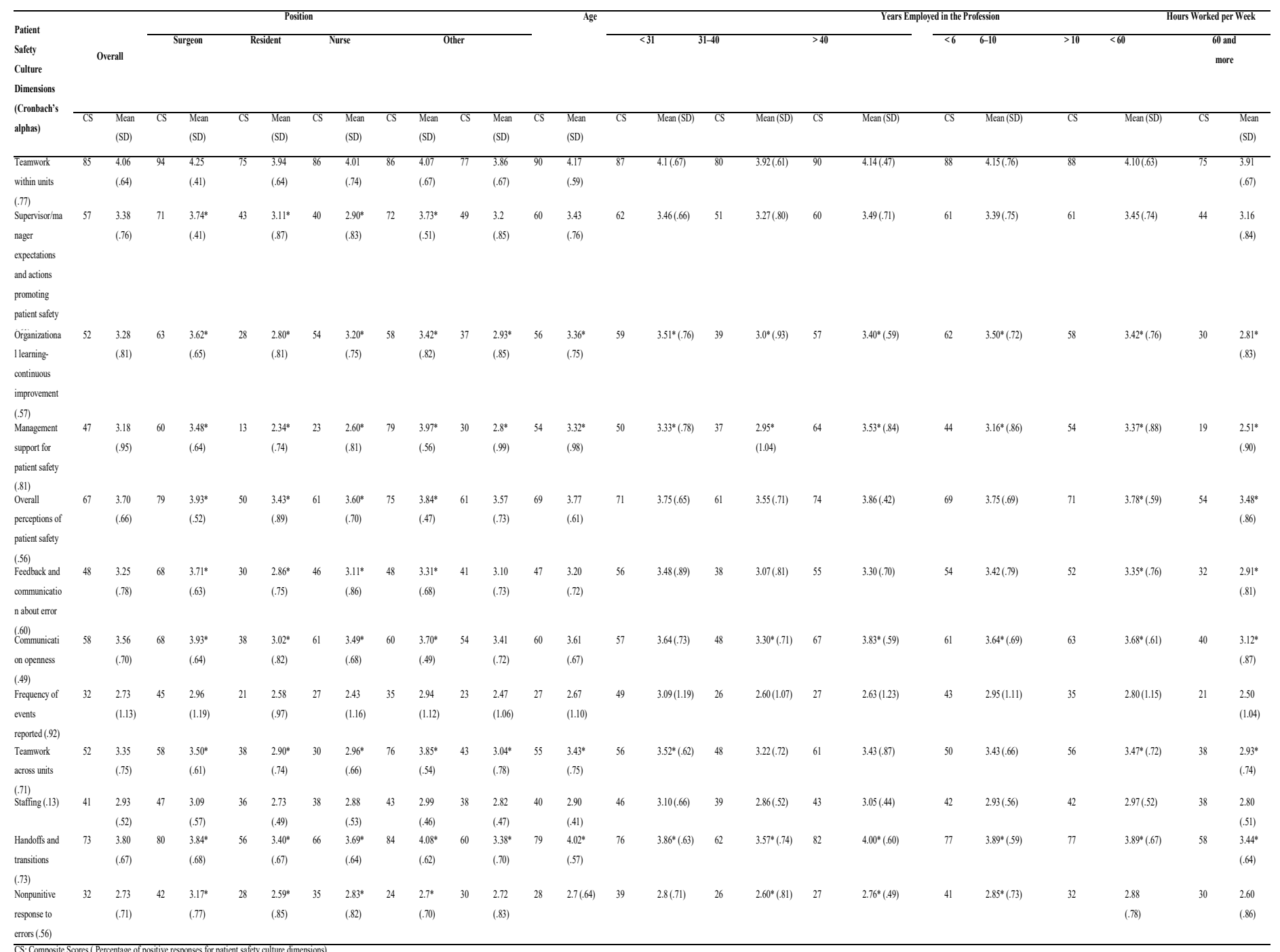

CS: Composite Scorese (Percentage of positive responses for patient safety culture dimensions)

SD: Standard Deviation

*Statistically significant at $p<.05$

There was a statistically significant difference in the patient safety grades assigned by staff in different positions; however, no significant difference was found by age, years employed in the profession, or hours worked per week. The nurses assigned more poor or failing patient safety grades to their units than the participants did from the other groups (Table 3). 
Table 3. Patient safety grade by participants' characteristics.

\begin{tabular}{|c|c|c|c|c|c|c|c|}
\hline & \multicolumn{6}{|c|}{ Patient Safety Grade } & \multirow[b]{3}{*}{$p^{*}$} \\
\hline & \multicolumn{2}{|c|}{$\begin{array}{l}\text { Excellent or } \\
\text { Very Good }\end{array}$} & \multicolumn{2}{|c|}{ Acceptable } & \multicolumn{2}{|c|}{$\begin{array}{l}\text { Poor or } \\
\text { Failing }\end{array}$} & \\
\hline & $\mathrm{n}$ & $\%$ & $\mathrm{n}$ & $\%$ & $\mathrm{n}$ & $\%$ & \\
\hline \multicolumn{8}{|l|}{ Position } \\
\hline Surgeon & 10 & 38.5 & 14 & 53.8 & 2 & 7.7 & .004 \\
\hline Resident & 6 & 25.0 & 12 & 50.0 & 6 & 25.0 & \\
\hline Nurse & 7 & 20.6 & 14 & 41.2 & 13 & 38.2 & \\
\hline Other & 19 & 47.5 & 19 & 47.5 & 2 & 5.0 & \\
\hline \multicolumn{8}{|l|}{ Age } \\
\hline$<31$ & 10 & 29.4 & 17 & 50.0 & 7 & 20.6 & 920 \\
\hline $31-40$ & 19 & 34.5 & 25 & 45.5 & 11 & 20.0 & \\
\hline$>40$ & 13 & 37.1 & 17 & 48.6 & 5 & 14.3 & \\
\hline \multicolumn{8}{|c|}{ Years Employed in the Profession } \\
\hline$<6$ & 15 & 31.9 & 23 & 48.9 & 9 & 19.1 & .710 \\
\hline $6-10$ & 11 & 33.3 & 18 & 54.5 & 4 & 12.1 & \\
\hline$>10$ & 16 & 36.4 & 18 & 40.9 & 10 & 22.7 & \\
\hline \multicolumn{8}{|c|}{ Hours Worked per Week } \\
\hline$<60$ & 35 & 36.1 & 46 & 47.4 & 16 & 16.5 & .445 \\
\hline 60 and more & 7 & 25.9 & 13 & 48.1 & 7 & 25.9 & \\
\hline
\end{tabular}

${ }^{*}$ Corrected Chi-Square Test

A two-dimensional multiple correspondence analysis was performed in a simplified way to examine the coherence and relationship between all the participants' characteristics and the overall patient safety grade (Figure 1). To achieve goodness of fit of the model, it is sufficient to show that nearly $33 \%$ of the total inertia is explained by the dimensions used in the multiple correspondence analysis. The term "inertia" corresponds to variance in multiple correspondence analysis and it indicates how much of the total variance is explained by each dimension. ${ }^{24}$ The total inertia was 2. The first dimension explained $27.98 \%$ of the total inertia while the second dimension explained $14.06 \%$. One may conclude that the total inertia of $42.04 \%$ for these two dimensions was sufficient for the model to be a good fit. The results of the multiple correspondence analysis illustrated in Figure 1 show that the nurses assigned a patient safety grade of failing/poor to their units. However, the surgeons and the participants in the other groups with $\geq 6$ years of employment in their profession, were $\geq$ aged 31 , and worked 60 and more hours/week, assigned patient safety grades of excellent/ very good or acceptable to their units. The residents were $<31$ years old, had $<6$ years of employment in the profession, and worked 60 and more hours/week. 


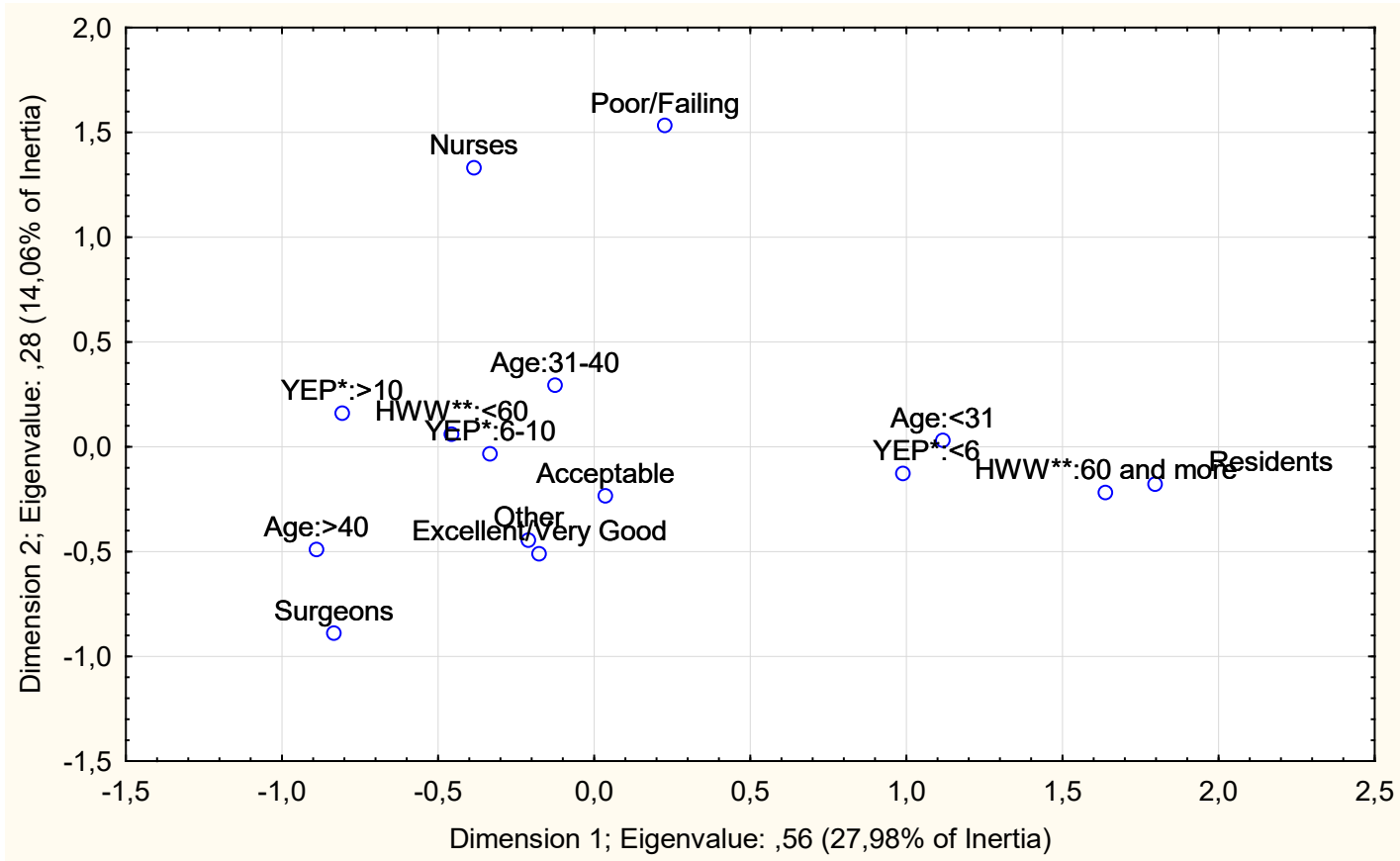

*YEP: Years Employed in the Profession

**HWW: Hours Worked per Week

Figure 1. Evaluation of the staff's characteristics and patient safety grades using multiple correspondence analysis

The relationships between patient safety grade and dimensions of patient safety culture were analyzed using the Eta coefficient. The results are shown in Table 4. Significant differences were found between the mean scores on all the patient safety culture dimensions, except "staff- ing" and "nonpunitive responses to errors", and patient safety grade. There was a positive though moderate relationship between many of the dimensions of patient safety culture and patient safety grade. Therefore, these results support the validity (construct validity) of the HSPSC.

Table 4. Comparison of the dimensions of patient safety culture by patient safety grades.

\begin{tabular}{|c|c|c|c|c|c|}
\hline \multirow{3}{*}{ Patient Safety Culture Dimensions } & \multicolumn{3}{|c|}{ Patient Safety Grade } & \multirow[b]{3}{*}{ p } & \multirow[b]{3}{*}{ Eta } \\
\hline & $\begin{array}{l}\text { Excellent/Very } \\
\text { good }\end{array}$ & Acceptable & Poor/Failing & & \\
\hline & Mean (SD) & Mean (SD) & Mean (SD) & & \\
\hline Teamwork within units & $4.29(.63)$ & $3.98(.53)$ & $3.84(.81)$ & .01 & .27 \\
\hline $\begin{array}{l}\text { Supervisor/manager expectations and } \\
\text { actions promoting patient safety }\end{array}$ & $3.58(.56)$ & $3.51(.71)$ & $2.68(.84)$ & .00 & .44 \\
\hline $\begin{array}{l}\text { Organizational learning-continuous } \\
\text { improvement }\end{array}$ & $3.65(.82)$ & $3.26(.60)$ & $2.68(.89)$ & .00 & .42 \\
\hline Management support for patient safety & $3.71(.88)$ & $3.16(.74)$ & $2.24(.86)$ & .00 & .53 \\
\hline Overall perceptions of patient safety & $4.05(.54)$ & $3.71(.51)$ & $3.11(.80)$ & .00 & .49 \\
\hline $\begin{array}{l}\text { Feedback and communication about } \\
\text { errors }\end{array}$ & $3.64(.66)$ & $3.23(.67)$ & $2.62(.84)$ & .00 & .45 \\
\hline Communication openness & $3.73(.58)$ & $3.62(.66)$ & $3.07(.85)$ & .01 & .34 \\
\hline Frequency of events reported & $3.31(1.00)$ & $2.54(1.07)$ & $2.17(1.10)$ & .00 & .39 \\
\hline Teamwork across units & $3.60(.71)$ & $3.36(.61)$ & $2.85(.91)$ & .00 & .35 \\
\hline Staffing & $2.91(.52)$ & $2.96(.51)$ & $2.91(.54)$ & .88 & .05 \\
\hline Handoffs and transitions & $4.01(.72)$ & $3.76(.54)$ & $3.46(.84)$ & .07 & .28 \\
\hline Nonpunitive responses to errors & $2.80(.87)$ & $2.90(.68)$ & $2.62(.94)$ & .36 & .13 \\
\hline
\end{tabular}




\section{Discussion}

Few studies have evaluated the patient safety outcomes by staff' characteristics that may affect patient safety culture in general surgery departments, as well as the relation between patient safety outcomes. To our knowledge, no studies have examined the relationship between hospital staff's characteristics and patient safety grades via multiple correspondence analysis.

The "frequency of events reported," "nonpunitive responses to errors," and "staffing" dimensions had the lowest means and composite scores. In many studies conducted in Turkey, these dimensions had generally the lowest means or composite scores. ${ }^{19,25,26}$ Residents and nurses, $<$ age 31 , with $<6$ years of employment in the profession, and who worked 60 and more hours/week had negative perceptions of patient safety culture in several dimensions of HSPSC. The resident group, which is generally composed of new graduates from the faculty of medicine, work more hours per week than the other staff because they are assigned to work many night shifts in their first year. The results of the multiple correspondence analysis showed that many of these participants who were $<31$ years old, with $<6$ years of employment in the profession, and worked 60 and more hours/week were residents. A study of 111 staff, including junior residents, senior residents, surgeons, nurses, scrub technologists, and anesthetists in an operating theater found that the surgeons' perceptions of patient safety culture were more positive than that of the residents. That study also found the perceptions of the senior residents (3-5 years of postgraduate training) were more positive than those of the new residents (1-2 years), which might have been related to differences in professional experience. ${ }^{27}$ The new residents might have a more negative perception of patient safety culture because they had a greater possibility of making errors. Their negative perceptions of the patient safety culture might also have been due to physical and mental fatigue and insomnia associated with working overtime, which increased their likelihood of making errors. Therefore, staff who are new in the profession should be given adequate orientation training when they start to work at the department, big responsibilities should not be given in the early days of their profession, and they should be supervised frequently by their superiors. A study in the US found that residents, who worked $\geq 80$ hours/week, had more exposure to accidents and injuries, were more prone to quarrels with other staff, and made more serious medical errors. Any failure in a resident's performance due to overtime work, insomnia, or stress may lead to errors that affect quality of care.28 Turkey's Ministry of Health, therefore, initiated the following article: "Residents shall not be forced to work night and weekend shifts, nor every other day periods or block periods; the shifts shall be arranged in a way to provide for the safety of the patients and the staff." This notice was released in 2011 with the goal of preventing adverse effects caused by overtime work. ${ }^{29}$

The perceptions of patient safety culture of the nurses, who had more interactions with patients than the other staff were also negative. Likewise, the nurses (38.2\%) assigned more poor/failing patient safety grades to their units than did the other participants. According to the multiple correspondence analysis, the nurses evaluated patient safety as failing/poor. Several studies of nurses in Turkey found that the most common type of medical error was hospital-acquired infections. Other common types of medical errors included diagnostic errors, needle or cutting tool injuries, medication errors, bedsores, and post-surgical complications. The nurses in these studies reported the main causes of medical errors were workload, fatigue, overtime work, and an inadequate number of nurses. ${ }^{30,31}$ In the "staffing" dimension in our study, which had the third lowest mean on the 12 dimensions of the HSPSC, the nurses' perceptions were more positive than those of the residents were and more negative than those of the surgeons and other staff. Turkey ranks the lowest among the OECD countries in terms of the number of nurses per 1,000 persons, being 1.8 in Turkey (the OECD average is 9.1). ${ }^{32}$ Nurses spend almost $90 \%$ of their time with patients.33 A study of nurses in Turkey reported that heavy workload was the most significant source of stress. ${ }^{34}$ A study by the Turkish Medical Association (2010) of 462 staff (256 physicians, 178 nurses, and 28 managers) reported the top five reasons for the occurrence of preventable medical malpractice. In descending order, they were heavy workload and workload stress, inadequate time for physicians to spend with patients, heavy patient load in health institutions, healthcare staff's lack of education, and an inadequate number of nurses. ${ }^{35}$ In surgical intensive care units and surgery departments 
in Turkey, $74 \%$ of the nurses stated that workload was heavy and the effect of workload on patient safety led to an increased risk of errors due to inadequate time to spend with patients, failure to take precautions due to overwork, fatigue, and inattention. ${ }^{36}$ Nurses usually have more interactions with patients than physicians in hospital settings, and patients generally spend more time with nurses during their inpatient stays. Nurses detect errors, such as hospital-acquired infections, medication errors, (e.g., wrong time, wrong dose, and wrong medication errors), complications, patient transfer errors, and patient identification errors more frequently. This may explain why the nurses' perceptions of patient safety were negative compared with other staff. In order to remove the adverse effects of nurses' workload on patient safety, the hospital managers should increase the number of nurses and should determine the number of nurses working in hospital units according to the workload.

A comparison of the dimensions of the patient safety culture and patient safety grades revealed differences on many dimensions; however, no differences in "staffing," and "non-punitive responses to errors" were found. The correlations between patient safety grade and these two dimensions were the lowest correlation coefficients. Cronbach's alpha for the "staffing" dimension was low $(\alpha=.13)$, which might have stemmed from cultural differences. There were no differences in the staffing dimension by staff's characteristics, except for the number of hours worked weekly. In this case, there were no differences in the staffing dimensions by patient safety grade because the participants did not answer the items on staffing consistently, and therefore, the correlation between them were low. However, the reason for the low correlation between "non-punitive responses to errors" and patient safety grade might have been the fact that the number of events to report was low.

In general, as patient safety grades decreased from excellent/very good to poor/failing, the means of the dimensions of patient safety culture also decreased. There was a positive though moderate relationship between patient safety grade and many of the dimensions of patient safety culture. Given the results, one may conclude that the means of most of the dimensions varied by patient safety grade and there was a positive, though moderate, relationship between patient safety grade and most of the dimensions, which enhanced the validity of the HSPSC. Thus, when there is a need to make a quick assessment of patient safety culture, asking only about the patient safety grades might provide a rough estimate of patient safety culture.

\section{Conclusion}

The level of patient safety culture in the general surgery departments of the study was medium. Improvements are required in the dimensions of "nonpunitive responses to errors," "frequency of events reported," and "staffing" because they had the lowest means, indicating negative perceptions. The nurses, residents, and others who worked more hours per week, were younger and had less experience, had more negative perceptions of patient safety culture than participants with other characteristics did. The nurses gave lower patient safety grades to their units. Hospital managers should examine in detail the reasons why these groups had a more negative perception of patient safety culture. To build a positive culture and to sustain it, managers must commit to patient safety. They may use several strategies, such as patient safety leadership walkrounds, safety briefings, teamwork training, and an incident reporting system to improve the patient safety culture. ${ }^{37}$

This study was conducted in one of the largest training and research hospitals in Turkey. However, the findings are limited to one hospital because the survey was conducted in only one hospital. Therefore, similar studies should be conducted in diverse hospitals to generalize the findings. Future research is needed to understand why nurses, residents, other participants who worked more hours/week, were younger, and had less professional experience had more negative perceptions of patient safety culture that other staff. The relationship between the study's results pertaining to patient safety culture and staff's clinical performance should also be examined. Multiple correspondence analysis is recommended for use in future studies on patient safety culture because it simultaneously analyzes all characteristics that might affect the patient safety grades. Since it would provide information about the validity of the HSPSC, it is suggested to compare dimensions of patient safety culture with patient safety grades and the relationship between them in future studies. 


\section{Conflict of interest disclosures}

None.

\section{Funding disclosures}

No funding was received for this study and there is no conflict of interest.

\section{Ethical approval}

The study was approved by both General Directorate of Treatment Services of the Ministry of Health of Turkey and the director of general surgery department of study hospital.

\section{Acknowledgments}

The authors thank the staff of the hospital where the study was conducted for their assistance in the administration of the survey. The Authors declare that there is no conflict of interest.

\section{References}

1. Sorra J, Dyer N. Multilevel psychometric properties of the AHRQ hospital survey on patient safety culture. BMC Health Serv Res. 2010; 10:199.

2. Institute of Medicine. To Err is Human: Building a Safer System. Washington: DC: National Academiy Press, 2000.

3. Deilkas ET, Hofoss D. Psyhometric properties of the Norwegian version of the safety attitudes questionnaire, generic version. BMC Health Serv Res. 2008; 8:191.

4. Seo, D. C., Torabi, M. R., Blair, E. H., \& Ellis, N. T. A cross-validation of safety climate scale using confirmatory factor analytic approach. Journal of Safety Research. 2004; 35(4), 427-445.

5. Sorra JS, Nieva VF. Hospital Survey on Patient Safety Culture. Rockville, MD: 2004, Agency for Healthcare Research and Quality, AHRQ Publication No. 04-0041.

6. The Ministry of Health of Turkey. Strategic Plan. 20122013. Ankara: 2012.

7. The Ministry of Health of Turkey. Quality Standards in Health - Hospital (Version 5). Ankara: 2015a.

8. The Ministry of Health of Turkey. 2015b. Available from: http://www.kalite.saglik.gov.tr/index. php?lang $=$ tr\&page $=51 \&$ newsCat $=3 \&$ news $I D=1210$

9. The Ministry of Health of Turkey. 2015c. Available from: http://www.kalite.saglik.gov.tr/index. php?lang $=$ tr\&page $=46 \&$ newsCat $=1 \&$ news $I D=1232$
10. Pronovost PJ, Weast B, Bishop K, Paine L, Griffith R, Rosenstein BJ, Kidwell RP, Haller KB, Davis R. Senior executive adopt-a-work unit: A model for safety improvement. Jt Comm J Qual Saf. 2008; 30 (2): 59-68.

11. El-Jardali F, Dimassi H, Jamal D, Jaafar M, Hemadeh N. Predictors and outcomes of patient safety culture in hospitals. BMC Health Serv Res. 2011; 11:45.

12. Yılmaz KB, Akıncı M, Şeker D, Güller M, Güneri G, Kulaçoğlu H. Factors affecting the safety of drains and catheters in surgical patients. National Surgical Journal. 2014; 30 (2): 90-92. doi: 10.5152/UCD.2014.2564

13. Shu Q, Cai M, Tao H, Cheng Z, Chen J, Hu Y, Li G. What does a hospital survey on patient safety reveal about patient safety culture of surgical units compared with that of other units? Medicine. 2015; 94 (27): 1-8.

14. World Health Organization. The Second Global Patient Safety Challenge: Safe Surgery Saves Lives. Geneva: 2008.

15. Agency for Healthcare Research and Quality, USA: 2015. Available from: http://www.ahrq.gov/professionals/quality-patient-safety/patientsafetyculture/hospital/ index.html

16. Sorra, JS. Patient Safety Culture in Hospitals, International Hospital Federation World Hospital Congress Dubai, United Arab Emirates: 2011.

17. Agency for Healthcare Research and Quality, USA: 2011. Available from: http://www.ahrq.gov/qual/ patientsafetyculture/hospdim.pdf.

18. Bodur S, Filiz E. A survey on patient safety culture inprimary healthcare services in Turkey. Int $\mathrm{J}$ Qual Health Care. 2009; 21 (5): 348-55.

19. Bodur S, Filiz E. Validity and reliability of Turkish version of "Hospital Survey on Patient Safety Culture" and perception of patient safety in public hospitals in Turkey. BMC Health Serv Res. 2010; 10:28.

20. Greenacre M, Blasius J. Multiple Correspondence and Related Methods. Chapman and Hall/CRC. London: 2006.

21. Alpar R. Applied Multivariate Statistical Methods. 4th Edition, Detay Publishing. Ankara: 2013. (Original work published in Turkish)

22. Özdamar K. Statistical Data Analysis with Software Packages. 9th Edition, Nisan Bookstore. Ankara: 2013(Original work published in Turkish)

23. Alpar R. Applied Statistics with examples from the Sports, Health and Education Science and Validity-Reli- 
ability. Detay Publishing. Ankara: 2014. (Original work published in Turkish)

24. Goodwill AM, Allen JC, Kolarevic D. Improvement of thematic classification in offender profiling: classifying Serbian homicides using multiple correspondence, cluster, and discriminant function analyses. J. Investig. Psych. Offender Profil. 2014; 11: 221-36.

25. Top M, Tekingündüz S. Patient Safety Culture in a Turkish Public Hospital: A Study of Nurses' Perceptions About Patient Safety. Syst Pract Action Res. 2015; 28: 87110.

26. Gündoğdu S, Bahçecik N. Determining Nurses’ Perception of Patient Safety Culture. Journal of Anatolia Nursing and Health Sciences. 2012; 15 (2): 119-128.

27. Putnam LR, Levy SM, Kellagher CM, Etchegaray JM, Thomas EJ, Kao LS, Lally KP, Tsao K. Surgical resident education in patient safety: where can we improve? I Surg Res. 2015; 199 (2): 308-13.

28. Baldwin DC Jr, Daugherty SR, Tsai R, Scotti MJ Jr. A national survey of residents' self-reported work hours: thinking beyond specialty. Acad Med. 2003; 78 (11): 115463.

29. The Ministry of Health of Turkey. Resident (assistants) of Circular No.2011/33, Thematic Edication and Working: 2011.

30. Alemdar DK, Aktaş YY. Medical error types and causes made by nurses in Turkey. TAF Prev Med Bull. 2013;12(3):307-14. doi:10.5455/pmb.1-1345816200

31. Özata M, Altunkan H. Frequency of medical errors in hospitals, determination of medical error types and medical errors: Konya sample. Thp Arasstermalar Dergisi. 2010; 8(2), 100-11.

32. OECD. Health at a Glance 2015: OECD Indicators. OECD Publishing. Paris: 2015.

33. El-Jardali F, Jamal D, Dimass, H, Ammar W, Tchaghchaghian V. The impact of hospital accreditation on quality of care: perception of Lebanese nurses. Int. J. Qual. Health Care, 2008; 20(5):363-71.

34. Önder G, Aybas M, Önder E. Determining the precedence order of the factors influencing nurses' stress level using multi criteria decision making techniques. Optimum Journal of Economics and Management Sciences. 2014; 1 (1): 21-35.

35. The Turkish Medical Association. Patient Safety: Turkey and World. Füsun Sayek TMA Reports. Ankara: 2010. (Original work published in Turkish)

36. Balanuye B. The effects of workloads of nurses whom work in surgical clinics on patient safety. Dissertation, University of Başkent, Turkey: 2014.

37. Frankel A, Graydon-Baker E, Neppl C, Simmonds T, Gustafson M, Gandhi TK. Patient safety leadership walkrounds. Jt Comm J Qual Saf. 2003; 29 (1): 16-26. 